\title{
Cliffs make a hasty retreat
}

Knowing how quickly coastlines have eroded is essential for quantifying the future risks to both infrastructure and coastal ecosystems. Writing in Proceedings of the National Academy of Sciences, Hurst et al. report retreat rates for cliffs on the south coast of Britain (pictured) over thousands of years, and show that this erosion has speeded up in recent centuries (M. D. Hurst et al. Proc. Natl Acad. Sci. USA http://dx.doi. org/10.1073/pnas.1613044113; 2016).

The authors combine high-precision isotopic dating with a detailed numerical model of coastal erosion. They find that retreat rates were relatively slow (2-6 centimetres per year) until a few hundred years ago before subsequently accelerating (reaching 22-32 $\mathrm{cmyr}^{-1}$ ), and suggest that this is driven by a combination of environmental and anthropogenic factors. The results show that a careful analysis of long-term coastal records can uncover more-recent changes, which will help in developing predictive models. Ryan Wilkinson

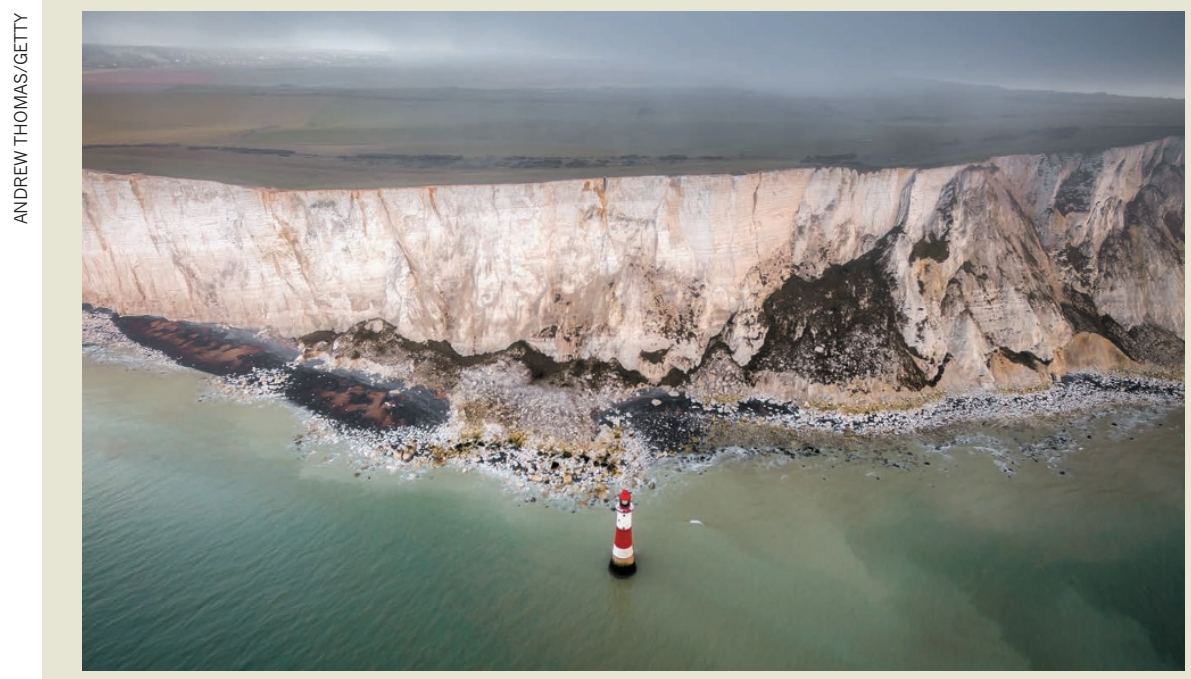

\section{Bad neighbours cause bad blood}

Expression of a blood-cancer-associated genetic mutation in the non-blood cells of the bone marrow is sufficient to cause blood cancer in mice. This finding could point to new approaches to treating an often-fatal disease. SEE LETTER P.304

\section{GORDON CHAN \& BENJAMIN G. NEEL}

$\mathrm{M}$ utations in blood stem cells can result in excessive production of one or more types of mature blood cell and a form of cancer called a myeloproliferative neoplasm. One such neoplasm is juvenile myelomonocytic leukaemia (JMML), a rare childhood disease characterized by expansion of the white blood cell population ${ }^{1}$. Currently, JMML can be treated only by stem-cell transplantation, but about $50 \%$ of patients relapse following this procedure. A more detailed understanding of the disease could lead to new therapies and improved outcomes. Dong et al. ${ }^{2}$ report on page 304 that mutation of the gene Ptpn 11 in the non-blood cells that surround blood stem cells causes a JMML-like cancer in mice, owing to altered interactions between these two cell types.

Mutations in genes that encode proteins of the RAS-ERK signalling pathway are found in the blood cells (but no other cells) of about $90 \%$ of children with sporadic JMML (refs 1, 3). The most frequent of these occur in the gene PTPN11 (refs 1, 3). Such mutations activate

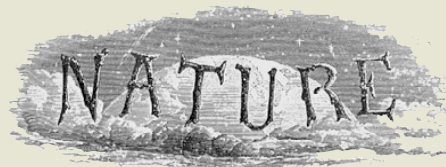

\section{Years Ago}

Recent reports on the chromosomes and total DNA of the chicken cell nucleus show that they differ from those of typical placental mammals in an unusual pattern of chromosome sizes and a DNA content equal to half of that of most mammals ... anomalies include incomplete dominance... and alteration of phenotypic sex without visible alterations in the karyotype. One explanation ... could be that three-fourths of the normal genetic dose occurs fairly frequently in the chicken. Three-fourths of the normal gene dose could occur if each of the arms of the major chromosomes in the chicken were isochromosomes ... which double back on themselves for transcription but straighten out and are apposed in the orthodox manner for meiosis ... A chromosome pair would provide four readings of the message, and a cell with three out of four of the normal readings might well be viable ... One evolutionary advantage of the looped isochromosome system proposed here might be that such a chromosome would be better able to withstand the damage to the DNA ... caused by the relatively high internal temperature of birds. From Nature 12 November 1966

\section{Years Ago}

In Nature of October 5 it is stated that the cause of the optical deterioration of the atmosphere in July and August "is for the time being still in doubt. Up to the present no reports of volcanic eruptions have come to hand from any part of the globe." I wish to state that in July a strong outburst occurred of the Stromboli volcano ... there was an extraordinary eruption of fluid and incandescent lava to a great height, followed by a thick rain of lapilli and ashes.

From Nature 9 November 1916 